\title{
A COMBINED APPROACH FOR SURVEYING COMPLEX COASTAL SITES
}

\author{
M. Liuzzo, R. Feo, S. Giuliano, V. Pampalone \\ KORE University of Enna, Enna, Italy, (mariangela.liuzzo, roberto.feo, sebastiano.giuliano, vincenzo.pampalone) @unikore.it
}

\section{Commission II}

KEY WORDS: Coastal Sites, Mobile Mapping System, 3D Laser Scanner, Echo Sounder Systems, 3D Models

\begin{abstract}
:
This study presents an integrated approach for reading coastal sites.

A process aimed at protecting and enhancing these sites must be developed alongside a targeted interdisciplinary strategy, closely linked to the fields of archaeology, survey, landscape reading, morphology of the territory and geology. These must no longer be managed as individual cognitive elements, but within a single comprehensive analytical interpretation model.

The experiment activity carried out along the rocky area of Aci Castello, on the eastern coast of Sicily, was developed using a methodological approach based on the integration of 3D data coming from various survey technologies - 3D laser scanning, mobile mapping and echo sounder systems. The aim of the experiment was to create a complete three-dimensional model of the studied area, focused on obtaining a dynamic understanding, that is punctual and comprehensive, of the site's value and fragility.
\end{abstract}

\section{INTRODUCTION}

The coasts along our territory are stratified areas, rich in charm, of complex geomorphology and wide dimensions, characterised by the condition of being border areas between land and sea. They have become overtime more at risk of damage from natural events and incessant human action. It is therefore increasingly urgent that procedures are developed for the monitoring, conservation and valorisation of the coastlines. At the moment such a systematic, comprehensive and precise system aimed at the safeguarding and active enhancement has still not yet been developed.

This is attributable to the current lack of uniform procedures that are capable of monitoring the complex interaction of numerous elements of wealth and of vulnerability that characterise these areas. An integrated interdisciplinary approach is necessary. The approach must be closely linked to the areas of archaeology, history, survey, reading of the landscape, territorial morphology, geology, analysis of the environmental and hydraulic qualities, which can no longer be considered independent cognitive elements - different in scale, setting and language code - but different parts of a single analytical interpretive model.

With the objective of creating a strategic convergence between the requests of the territory and technological innovations, an experimental investigative activity has begun on the emblematic coastal area of Aci Castello, on the eastern coast of Sicily. The choice of this test-site depends on the evident difficulty in studying its morphology while, at the same time, the need to urgently begin appropriate protection strategies. ${ }^{1}$

\section{RELATED WORKS}

A vast range of instruments and survey procedures are commercially available due to the remarkable development during recent decades. These instruments and procedures are capable of managing data at the geodesic and topographic scale as well as one of detail. They are highly precise, versatile and often equipped with high performance data acquisition, management and elaboration software. Less widespread and indepth, though, is the possibility of utilising these techniques together with each other and therefore being able to overcome the historical distinction between topographic field and architectural survey field, between territorial scale and scale of detail, between above and below sea levels.

By focusing attention particularly on the monitoring and protection of the coastal sites, it's easy to see the impact that remote sensing instruments with the development of different monitoring techniques from remote platforms, particularly from satellites and planes, have had on the important progress research. (Lillesand et al., 2007; Pranzini et al., 2008)

Such techniques make it possible nowadays to scientifically read ample portions of the territory, compatibly with the cartographic representations, with a special zenith view from above. The three dimensional nature of the data acquired doesn't impede, though, the possibility of other spatial viewpoints.

The fractal nature of many costal sites and their characteristics of risk and of value make it necessary to integrate the data collected using these techniques with other data gathered by closer range scale and points of view.

The development of mobile mapping technology is very interesting for closer readings of topos due to its significant advantages, which include the possibility to rapidly survey georeferenced areas with an elevated density of three dimensional points. The majority of the developed applications are concerned

\footnotetext{
1 The experimental campaign was carried out by the Survey and Representation Laboratory of the Enna Kore University, in particular by a team of engineers, architects and geologists under the responsibility of Prof. Mariangela Liuzzo. The interdisciplinary collaboration with the same university's Environmental Hydraulic Laboratory allowed for bathymetric surveys.
}

CREDITS - M. Liuzzo: Introduction, Related Works, The Experimental Integrated Survey Campaign, Conclusions; R. Feo, V. Pampalone: The Morphobathymetric Survey; R. Feo: The Geological 3D Analysis; S. Giuliano: The Survey of the Above Sea Level Site, The Integration Phase of the Data, The Multi-thematic Model. 

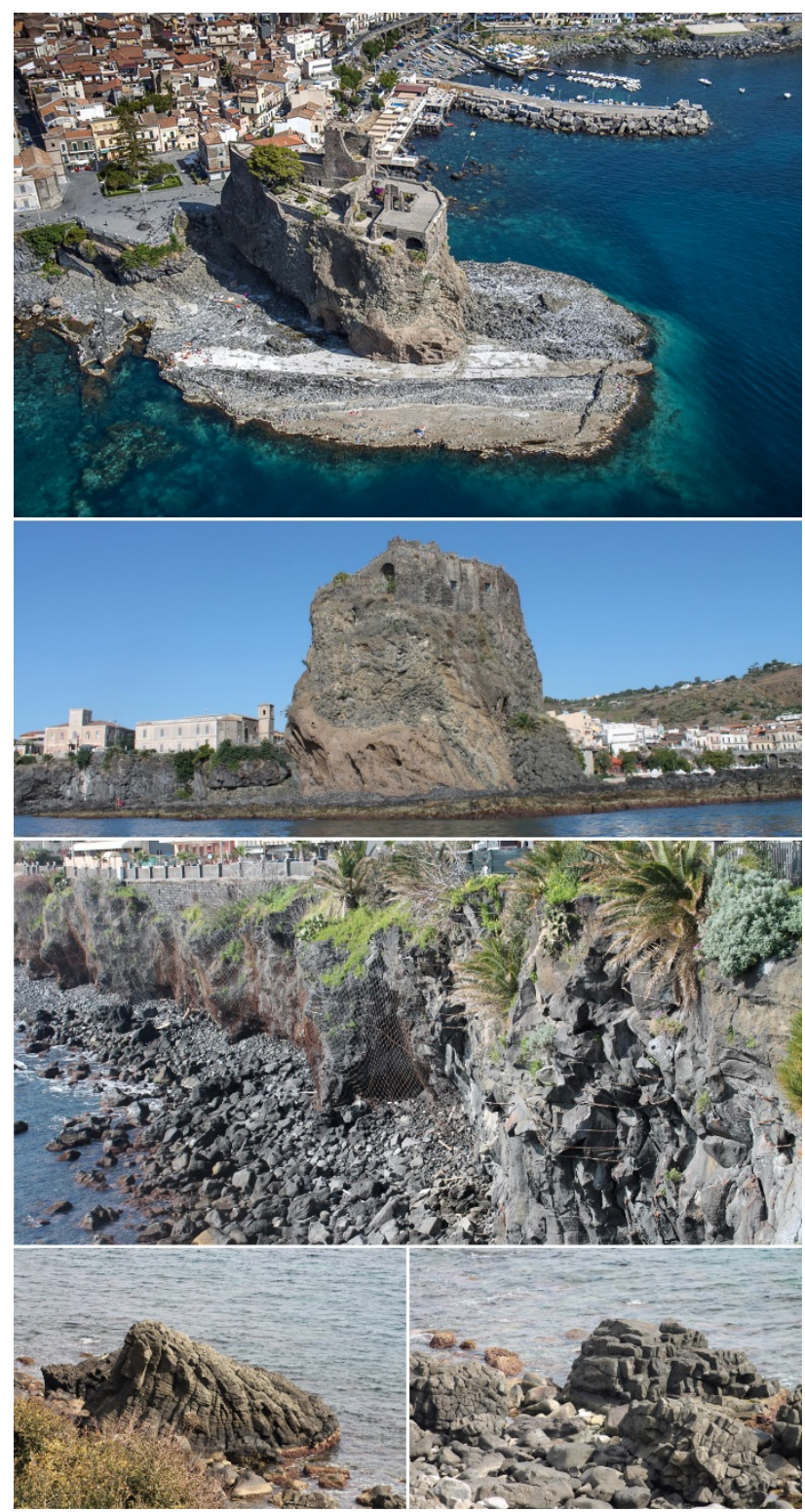

Figure 1: Aci Castello, images of the morphological articulation of the lava coastline and of the Aci castle (Luigi Nifosi)

with road side acquisition, often aimed at expedited updating of data predominantly onto cartography. However, what is worth mentioning is the experimentation carried out a few years ago in Venice for a study of the facades of the architectural patrimony that overlooks the Grand Canal, by mounting a system of mobile mapping onto a boat. (Adami et al., 2011)

This experiment though did not deal with the survey of the submerged part of the Grand Canal. For this reason, the bathymetric studies, related to both echo sounder (Perzia et al., 2011) and Lidar (Chust et al., 2010) survey techniques, are of great interest.

Taking into account the experience gained both nationally and internationally, an experimentation was developed for the coastal site of Aci Castello, geared towards integrating various survey techniques. The possibility to survey the coasts by taking advantage of the sea - that up until now had seemed a limit - was an opportunity to test. The aim of the integrated survey was to obtain a 3D model capable of analysing and documenting a coastal site, in line with different scientific themes and scales.

\section{DEVELOPED METHODOLOGY}

\subsection{The Experimental Integrated Survey Campaign}

Aci Castello is an ancient seaside village, historically tied to the strategic and monumental presence of a castle overlooking the sea (Figure 1)

The coastline is formed, in the section south of the Aci castle, by high basaltic cliffs, part of which jut out towards the sea while the other part is protected by sections of beach of varying expanse. The section north of the castle, is instead formed by low cliffs with sections of beaches that seem to almost be sculptured and strips of lava flow, that disappear below the water.

At the centre of all this, at the top of a massive rock formation held up by a natural platform, barely skimming the water, the castle of Aci is strategically situated. It was built using the same lava that the rocky coastline, on which it seems to literally emerge out of with an extraordinary geometrical - material naturalness.

This ancient heritage site at present has been classified, according to the Hydrogeological Structure Plan of the Sicilian Region, as an area of high risk and danger. Furthermore, adding to the hydrogeological risk, is the risk produced by the constant human presence along the coastline as well as that of the seaside tourism that is not adequately informed on the value and intrinsic frailty of the area. (Trimarchi et al., 2007)

The near complete lack of documentation, of a thorough and reliable survey of the area, is certainly ascribable to multiple factors: the undeniable problem in the geometric - spatial control of the lava front bluff rising sharply from the sea, high and morphologically structured; the scarceness of adequate space in front where to set up an ideal instrumental survey; the extremely low reflectivity matter of the rock to survey using terrestrial Lidar system and the lack of direct and visual access to large parts of the rocky coast, which are perceivable only from the sea.

The only exception was a Lidar survey (ATA 2007-2008 flight, commissioned by the Regional Department of Territory and Environment of the Sicilian Region), that involved a Digital Elevation Model, with 2x2 meter pace, of all the Sicilian territory, and the relative metered digital orthophoto, with $25 \mathrm{~cm}$ resolution.

Despite allowing such material to be used for a general overview, for several interpretive territorial readings and for the planning of the survey campaign, it is undeniable how the investigated phenomena have made a close range analysis necessary, with a prevalent frontal point of view.

The first experiment was carried out with mobile mapping surveys from both a boat and a car. This experiment was made possible by the generous willingness of several important production companies of the above mentioned survey system as well as of the alignment of interests between the municipality of Aci Castello and the Enna Kore University.

Several advantages drove the decision to mount a Lidar system onto a boat. First of all, unlike a photo-modelling survey by drone, there was no need for flight authorization, or the need to always sight operate along a morphologically complex site. Secondly, unlike a photo-modelling survey by boat, the optimization process of the trajectory made it possible to reach a precision range in the survey that was controlled and uniform, even for the areas that were more arduous and only visible from restricted viewpoints. Moreover, from an economic perspective, the system used was notably more expensive and the choice could be justified based on the specific goal of the survey, for example geognostic monitoring.

This was the first fundamental step in a campaign of broader surveys. The work was, in fact, integrated with a campaign of three-dimensional georeferenced terrestrial laser scans with GPS positioning and had a dual purpose. On one hand, it was to test 
the precision limits of the mobile technology, especially with reference to the control of the navigational trajectories. On the other hand, it was to integrate the data through additional portions of survey of the internal areas of the castle and of the areas not reached by the movement scans.

Moreover, a critical evaluation of the initial graphic elaborations that were produced clearly demonstrated the fact that the sea could not be considered the actual area limit, but rather that a strong continuity existed between the realities above sea-level and below sea-level.

Such understanding was fundamental in the decision to integrate the study with a bathymetric survey that had already been carried out for the portion of the sea floor around the area of the castle.

The challenge in using the different techniques was in creating a complete three-dimensional model of the studied area through the delicate integration of data originating from different sensors, taking advantage of the potential of each individual instrument, evaluated in terms of implementation field, optimal range and precision (Figure 2).

Such a challenge had to, furthermore, deal with various problems. First of all, there is the range of software and procedures that each sensor of measurement carries with it. Then there is the issue of needing to load the data onto files that can be shared and can also interact with one another. Finally there is the significant size of a three dimensional model to manage, that aims to interpret the studied area as a whole and in detail.

\subsection{The Survey of the Site Above Sea Level}

The survey campaign of the site above sea level of Aci Castello had as its objective to simultaneously highlight the territorial, urban and monumental characteristics, as well as the anthropic and natural elements, within their changing interactions. The detailed planning of a precise operating protocol - related to methods, time, precision range and choice of control points made it possible to work in a coherent manner in two distinct methodical and chronological phases: an initial acquisition of data, in mobile mapping mode, and a secondary phase, with terrestrial 3D laser scanning.

The mobile mapping survey ${ }^{2}$ made it possible to obtain data spread out over both the rocky coast, as well as the nearby inhabited area. Lidar and photographic measurement sensors were both used. They were mounted onto moving vehicles (cars and boats) and adequately paired with GPS positioning systems, in kinematic mode, and with inertial measurement unit, for controlling the orientation and trajectory of the vehicles.

Closed trajectories, whenever possible, were found to be advantageous for the optimisation of the trajectories in the postprocessing phase. Post-processing operations highlighted a simpler precise control of the trajectory of the car system, also thanks to the connection to an odometer placed on the tires. The data from the boat, in fact, was greatly affected by the movement of the water, even though it was partially removed by the action of the inertial measurement unit $(100 \mathrm{~Hz})$

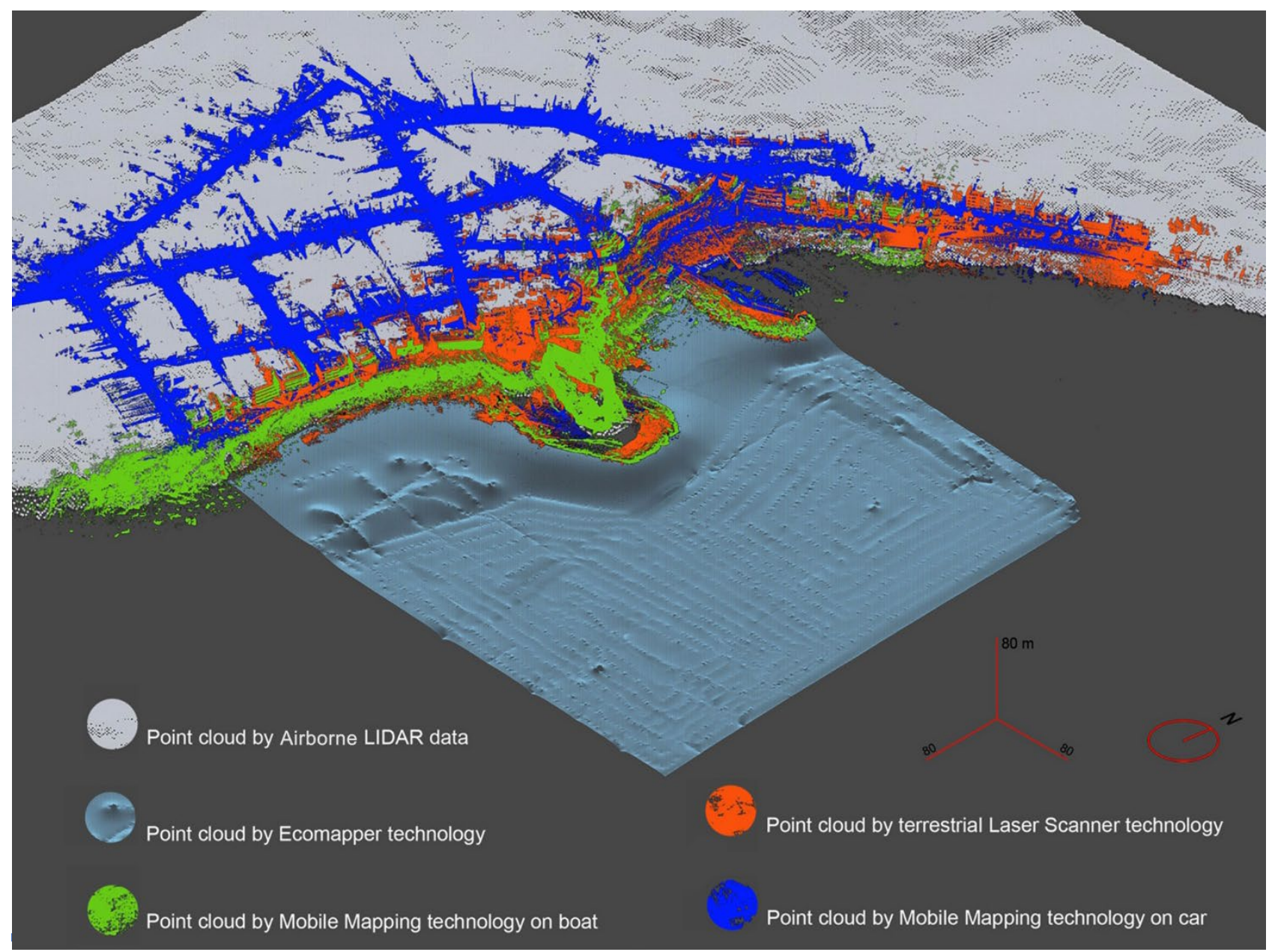

Figure 2: Aci Castello, 3D map of the combined surveying technologies.

${ }^{2}$ The following systems were tested on the same portion of the territory: Leica Pegasus SM70, with an HDS7000 phase shift scanner for car or boat; Riegl MSLVZ400 integrated with a VZ400 model time of flight sensor for car and boat; TOPCON IP-S2 for car. 
The survey campaign with terrestrial laser scanner technology was carried out using a time of flight range instrument, Leica ScanStation C10 model, that offered the best compromise between range and detail requested by the site. The topographic survey was carried out with the GNNS system, Leica Viva GS15 model, in Real Time Kinematic (RTK) setting, integrated in real time with laser scanner data ${ }^{3}$.

Concluded the data gathering phase, an initial separate postprocessing procedure was carried out, with proprietary software for each measurement sensor.

Trajectories and 3D data related to the mobile mapping systems, therefore, were processed thanks to the support of the technical teams of the measuring systems utilized. The 3D point clouds obtained were subsequently overlapped with the data originating from the terrestrial laser scanner. This test was capable of signalling areas of low precision positioning, corresponding to less satellite coverage or momentary problems of RTK correction of the GPS information.

Data from the terrestrial 3D laser scanner survey was processed using the Leica Cyclone software, with a dual phase that guaranteed a pre-alignment of all the scans to the GPS geographic position with an overlapping precision equal to the centimetric precision, and further optimization, tied to the automatic

recognition of the average forms of the overlapping areas among the different point clouds. This made it possible to achieve millimetric precision, maintaining the connection to the geographic coordinates.

\subsection{The Morphobathymetric Survey}

The morphobathymetry of the sea floor in front of the Aci castle was obtained by means of the Autonomous Underwater Vehicle (AUV) EcoMapper by YSI. ${ }^{4}$ It is equipped with a single beam echo-sounder and a side scan sonar, to obtain morphobathymetric data, that is connected and integrated with navigation and positioning systems. Together with the above-mentioned equipment, the software suite VectorMap is used in order to quickly plan the drone mission.

The Aci Castello mission was draw on the WGS84 georeferenced orthophoto taken between 2007 and 2008. The navigation path was created by linking 141 waypoints. The average vehicle speed was set to 3 knots and the acquisition frequency to 1 point per second, resulting in 12,885 points. Each point refers to $5 \mathrm{~m}^{2}$ by considering an overall study area of about $0.1 \mathrm{~km}^{2}$.

When the navigation was on the water's surface, the altimeter acquired the bathymetry, while the side-scan sonar gathered the images when the EcoMapper was $2 \mathrm{~m}$ under the water's surface. The mission was carried out with a small craft as an additional deployment service. The position fixing was guaranteed by an average of nine satellites. The estimated navigation time was 2.5 hours, but the actual time was 3.5 hours due to the strong current conditions which influenced the AUV speed. Thanks to the navigation equipment though, it did not affect the path direction. Post processing and data analysis were accomplished using ArcGIS software where a Digital Elevation Model (DEM) was created by means of a geostatistical analyst tool through the Ordinary Kriging algorithm. The spatial interpolation is based on self-correlation of a physical characteristic, or rather, the assumption that the same characteristic can change in space with continuity. The value, calculated for an unknown point, is determined through a weighted average of the known values,

\footnotetext{
3 The equipment belongs to Enna KORE University's Survey and Representation Laboratory. The survey was carried out by Mariangela Liuzzo, Sebastiano Giuliano, and Salvatore Savarino.
}

using specific coefficients determined by suitable semivariograms, which is the function of the spatial relationship between the measured values in the neighbourhood of the unknown point (Cressie, 1988).

\subsection{The Integration Phase of the Data}

Upon ending the post-processing phases related to the single sensors, it was necessary to find a better way of integrating all the data, ideally choosing a single software procedure.

The final choice was to use the software Leica Cyclone and Cloudworks, and 3DReshaper that, during the intermediate experimental test, was better able to manage a large amount of data that was structured with topographic information, i.e. with point coordinates represented by very elevated numbers.

All 3D points, in part originally obtained in UTM (WGS84), were converted to Gauss-Boaga coordinates, in order to have coherent conformity with the Sicilian Regional Technical Map, with LIDAR survey and the relative 2007-2008 orthophotos.

Every point cloud model relative to a single sensor was therefore imported by a suitable procedure and, in conclusion to a very delicate experimental multi-step procedure of unification and optimization, all data was inserted in a single point cloud model of the area (Figure 3, above).

\subsection{The Multi-Thematic Model}

The aim of the experiment was to create a complete threedimensional model of the studied area, aimed at dealing with the in-depth and multidisciplinary understanding of the site.

A similar comprehensive three dimensional multi-thematic (Figure 3) and multi-scale model (Figure 4) was interpreted as an instrument-document, always applicable in its content and updatable over time, on which to carry out all of the synchronic and diachronic analyses useful for the understanding of the studied area.

Information for these analyses came from both traditional sources (cartographic and photographic) and surveys carried out with innovative technology. They were all overlapped and anchored to shared geographic data. The most appropriate geometrically projective system, level of precision and scale of representation were adopted for each. A dynamic and flexible way of managing all information, which originated for various sources, made it possible to achieve an informative three dimensional system. This system is scientifically structured but yet, at the same time, capable of returning images that are both technically coded and of high divulging potential.

Selecting the model with the most suitable section planes allowed to hypothesise the reason for some mutual connections that were not evident from a simple overall view. These include the connections between the above and the below sea level morphologies and between the geometric structure of the anthropic action and the complex fractality of the natural place.

A further step involved the development of a close scaled mesh model of the castle area.

The detailed modelling of the castle elements - both built and natural - turned out to be particularly interesting (Figures 4, 5).

The modelling procedure, which was carried out by creating triangular surfaces moulded onto the point clouds, resulted in being extremely efficient. In particular, it made it possible to reproduce the complex surfaces of the rocky walls, avoiding

\footnotetext{
${ }^{4}$ The equipment belongs to the Enna KORE University's Environmental Hydraulic Laboratory. The survey was conducted by Giuseppe Barbera, Roberto Feo and Vincenzo Pampalone.
} 
The International Archives of the Photogrammetry, Remote Sensing and Spatial Information Sciences, Volume XLII-2/W9, 2019 8th Intl. Workshop 3D-ARCH “3D Virtual Reconstruction and Visualization of Complex Architectures", 6-8 February 2019, Bergamo, Italy

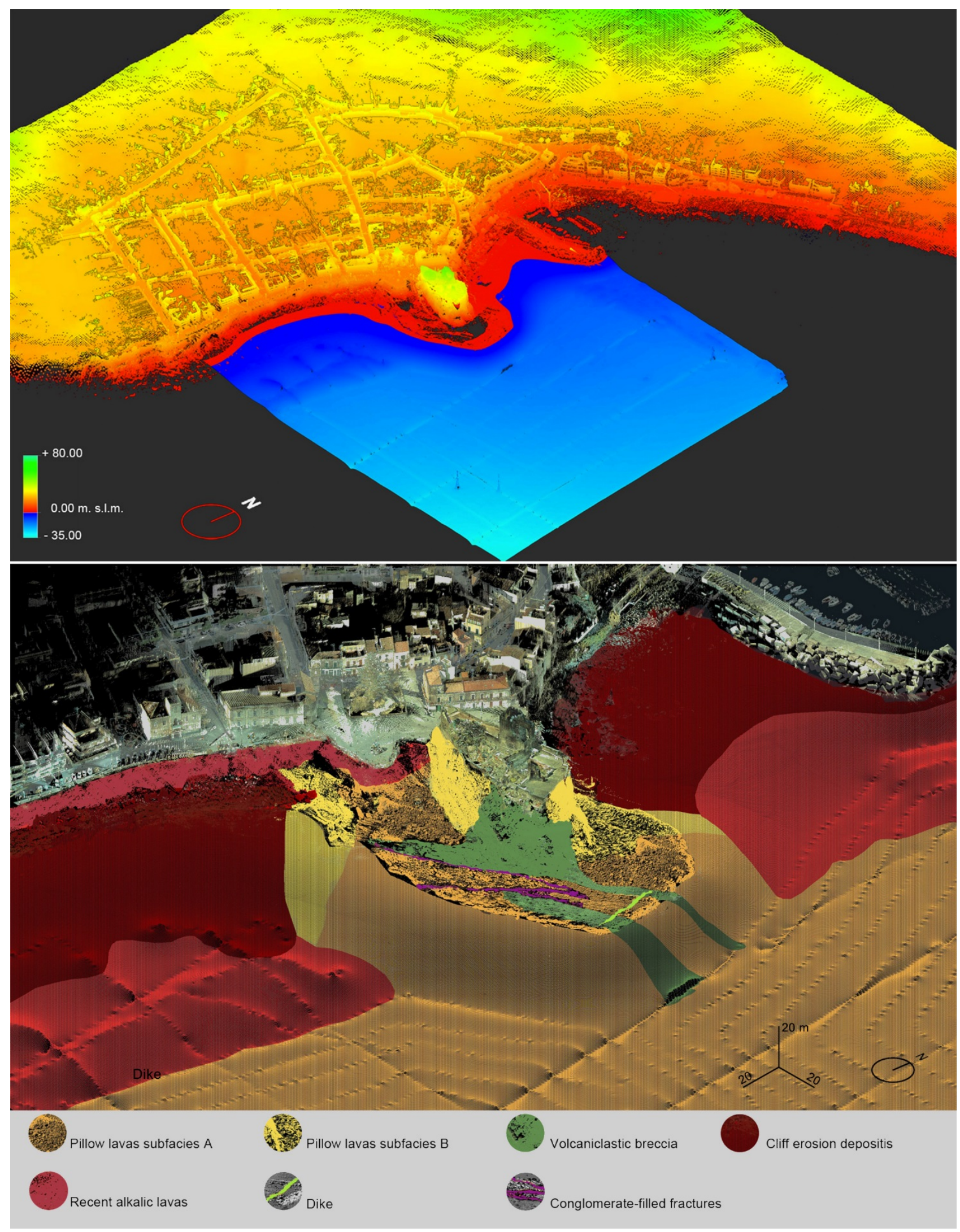

Figure 3: Multi-thematic readings of the Aci Castello coastal site: above, 3D elevation map; below, 3D geological map. 
schematic processes of simplifying the morphology into simplified geometries.

The main critical issues of this modelling method are essentially tied to the managing of the files of significant dimensions, directly proportional to the complexity and expanse of the amorphous surface as well as to the level of precision that the model is set to obtain. The breaking down of the model into two systems - the irregular one of the rock and the regular one of the architectural system - attributable to different layers solved this problem. This choice allowed to set the parameters, in a focused manner, for the reduction of the detail of the two different mesh. Considering that the mesh resolution is closely related to the point cloud resolution and that a greater detail leads to greater difficulty in managing the file, deciding if and in which part of the model to implement the morphologic definition - varying, simply and in a reversible manner, the form reduction parameters - become fundamental.

The following step in the detailed modelling of the two systems, rocky and architectural, was the enrichment of the mesh surfaces with the chromatic data gathered during the photographic survey campaign. ${ }^{5}$

Furthermore, the realistic representation system thus obtained reduced the difference between the technical model, that required a certain amount of scientifically obtained information, and the realistic mimetic model. This multi-purpose model is therefore suitable for use in different contexts ranging from scientific survey to pure representation.

\subsection{The Geological 3D Analysis}

The multidisciplinary synergy among the research team made it possible to integrate the necessary survey, topographic, informational technology and geological competencies, aimed at creating a geological 3D map (Figure 3, below). It is based on previous geological studies (Corsaro et al., 2000) and on the direct observations of the point cloud model. In this way everything that the traditional maps represented as two dimensional, was represented with more clarity in the three dimensional model.

The combined approach for surveying herein presented has provided a $3 \mathrm{D}$ model of the emerged area, that made it possible to recognize the lithofacies of the castle rock and of the coastline. In extreme synthesis, the transition from pillow lavas to volcanoclastic breccia, as well as the presence of the dike and the conglomerate-filled fractures, result as particularly evident. Furthermore, the vertical transition between pillow lavas and the more recent lavas as well as the costal erosion evidences were also assessed. The proposed approach therefore presents a higher level of detail, both three dimensional and chromatic, than just a single technology such as aerial survey, classical terrestrial or aerial photogrammetry interpretation could ever provide.

The morphobathymetric analysis of the sea floor in front of the town of Aci Castello shows different zones. The seafloor is characterized by pillow lavas and the peaks could be considered small eruptive spots.

This experimental activity shows that an integrated remote sensing approach is representative of the new frontier of improving geological analysis of areas characterized by a high variety of lithotypes and structural aspects and to assess the geomorphological hazard in extreme conditions by reducing time and cost.

\section{CONCLUSIONS}

The research activities launched in Aci Castello provided interesting results as well as points to reflect on for future studies. The necessity for an ulterior study on the combined way of surveying came about from the integration phase of the data. This is aside from the individual sensors used, which will be better performing in future applications. More importantly, for the border section between the emerged area and the submerged one, it's necessary to improve new pairing methods that could connect with extreme precision what was surveyed just above and just below the sea level. This could be possible by either adopting a single shared positioning system, using suitable stationary targets placed on the outer edges of range poles that are partially submerged. Or, otherwise, adopting a precisely shared time of survey, by simultaneously using the same GPS system.

In any case, the research activities carried out in Aci Castello have reached the objective of creating a $3 \mathrm{D}$, multi-scale and multithematic, model that can efficiently document and interpret the coastal site with all of its numerous interacting elements.

On the one hand, this research foresees data sharing with an "occasional" public, using common entertainment applications on portable devices (smartphones and tablets). To this extent, turning models from high-poly to low-poly is fundamental while still being able to fulfil the major requirement which is, within a fixed range, to adhere to the original shape of the object (Merlo et al., 2013; Auer et al., 2014).

On the other hand, the validity of a comprehensive $3 \mathrm{D}$, multithematic and multi-scale, model and the direction of one of its ulterior developments can be assessed when the model itself will be shared with other technicians or local authorities in charge of managing and monitoring the territory.

The aim to provide an instrument that is useful over time makes it necessary to analyse in detail the procedure of gathering, storing and processing the data. The objective is to guarantee the best periodic updating procedures, that are fast and precise, of the comprehensive model and of all the two-three dimensional graphic elaborations connected to it. Not losing previous information, which can always be recuperated and analysed, will allow for diachronic readings, which are often sources of interesting considerations.

\section{ACKNOWLEDGEMENTS}

The authors thank the managers and technicians from Leica Geosystem, MicroGeo and TOPCON for having made this task with mobile mapping system possible; the municipality of Aci Castello for authorizations and logistical support; the Heads of the Hydraulic Laboratory, prof. Mauro De Marchis and Gabriele Freni, for having contributed to the improvement of the experimentation below the sea level.

The authors finally thank Salvatore Savarino, for his precious contribution during the various surveying and post processing phases, and Angela Scibetta for the 2D graphic representation of the Castle of Aci.

\footnotetext{
${ }^{5}$ The $3 D$ Reshaper software allows to create and modify mesh, even with photographic texture, and to generate metric orthophotos originating from structured point clouds.
} 


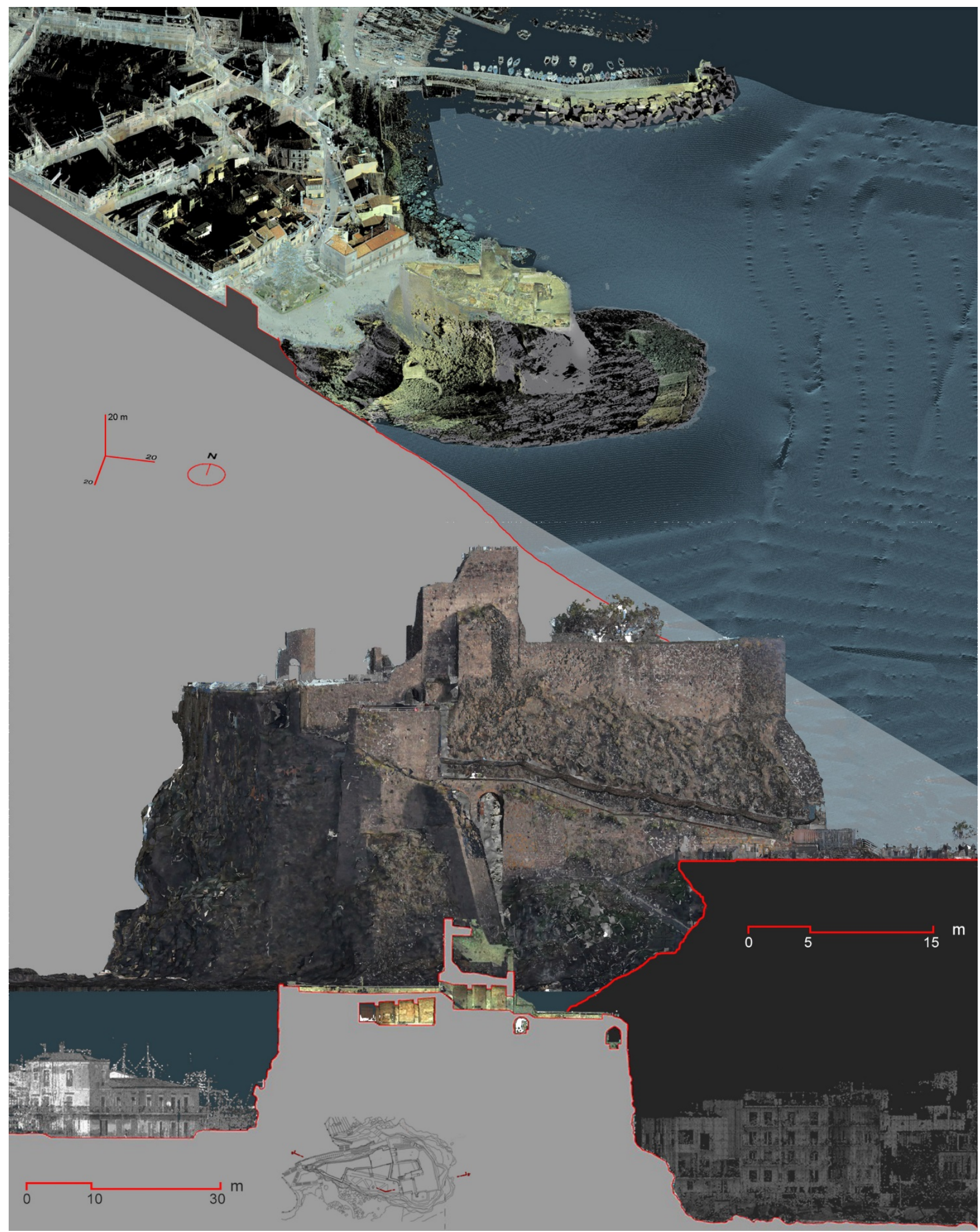

Figure 4: Multi-scale views of the 3D model of Aci Castello, to analyse the logic of any reciprocal spatial-morphological relationship between the natural site, urban settlement and historical monument. 


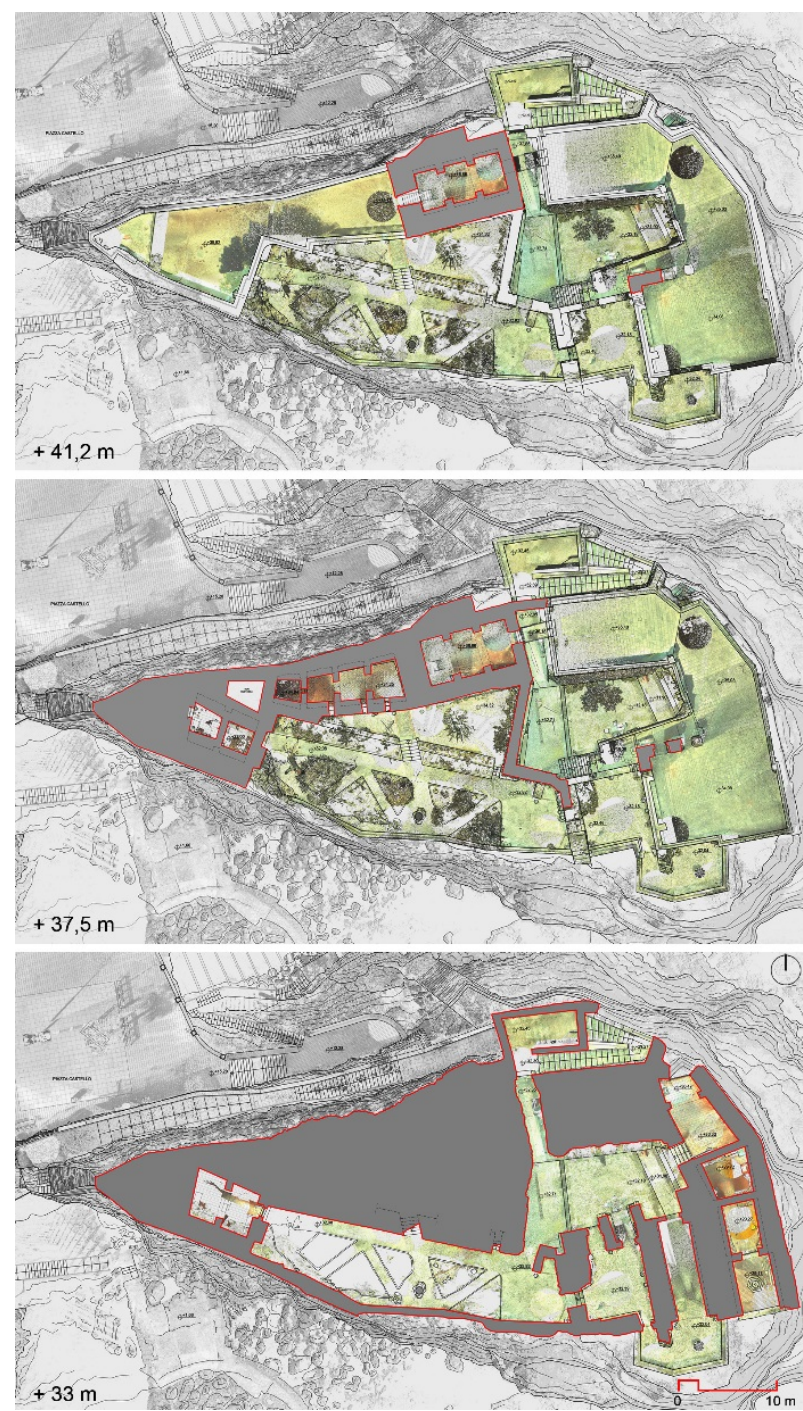

Figure 5: Aci castle, horizontal sections at different levels.

\section{REFERENCES}

Adami, A., Balletti, C., Guerra, F., Orlandini, S., \& Venier, P., 2011. Mobile laser scanning lungo i fronti veneziani del Canal Grande. In: 15a Conferenza Nazionale ASITA, Reggia di Colorno/Parma, Italy. http://atti.asita.it/ASITA2011/index.html.

Auer, M., Agugiaro, G., Billen, N., Loos, L., Zipf, A., 2014. Web-based Visualization and Query of semantically segmented multiresolution 3D Models in the Field of Cultural Heritage. In: ISPRS Annals of the Photogrammetry, Remote Sensing and Spatial Information Sciences, Vol. II-5, pp. 33-39.

Chust, G., Grande, M., Galparsoro, I., Uriarte, A., Borja, A., 2010. Capabilities of the bathymetric Hawk Eye LiDAR for coastal habitat mapping: A case study within a Basque estuary. In: Estuarine, Coastal and Shelf Science, Vol. 89 (3), pp. 200 213.

Corsaro, R.A., Cristofolini, R., 2000. Subaqueous volcanism in the Etnean area: evidence for hydromagmatic activity and regional uplift inferred from the Castle rock of Acicastello. In: Journal of Volcanology and Geothermal Research, Vol. 95, pp. 209-225.
Cressie, N., 1988. Spatial prediction and ordinary Kriging. In: Mathematical Geology, Vol. 20, pp. 405-421.

Gonçalves, J.A., Henriquescd, R., 2015. UAV photogrammetry for topographic monitoring of coastal areas. In: The International Archives of the Photogrammetry, Remote Sensing and Spatial Information Sciences, Vol. 104, pp. 101-111.

Grassi, M., Lamberti, L., Milli, M., Nobili, A., Rossi, M., Surace, L., 2007. Confronto tra rilevamenti batimetrici con laser aviotrasportato e ecoscandaglio multifascio: metodi e risultati. In: $11^{\circ}$ Conferenza Nazionale ASITA, Torino, Italy. http://atti.asita.it/Asita2007/Indice.html

Irish, J.L., Lillycrop, W.J., 1999. Scanning laser mapping of the coastal zone: the SHOALS system. In: The International Archives of the Photogrammetry, Remote Sensing and Spatial Information Sciences, Vol. 54(2-3), pp. 123-129.

Lillesand, T., Kiefer, R.W., \& Chipman, J., 2007. Remote Sensing and Image Interpretation, sixth edition. Hoboken, NJ, John Wiley \& Sons.

Liuzzo, M., Giuliano, S. \& Savarino, S., 2015a. Survey on the landscape and morphological singularities of the Cliff of Aci Castello. In: AA.VV. XIII International forum Le Vie dei Mercanti, Heritage and Technology, Mind Knowledge Experience, atti del convegno. Capri - Aversa, pp. 623-631.

Liuzzo, M., Giuliano, S., \& Savarino, S., 2015b. A methodical approach for the integrated reading of an urban place. The case study of Aci Castello. In: Marotta, A. \& Novello, G. (Ed.), Disegno e Città, Cultura Arte Scienza Informazione. Roma, Gangemi Editore, pp. 651-656.

Merlo, A., Fantini, F., Aliperta, A., Lavoratti, G., Lòpez Hernàndez, J.L., 2013. Texturing e ottimizzazione dei modelli digitali reality based: la chiesa della Compañía de Jesús. In: DISEGNARECON, Vol. 12(6), pp. XIV1 - XIV14.

Perzia, P., Falautano, M., Castriota, L., Cillari, T., Vivona, P., Toccacelli, P., Scotti, G., Andaloro, F., 2011. Indagine geomorfologica e bionomica dei fondali di Sciacca. In: Biogeographia - The Journal of Integrative Biogeography, Vol. 30(1), pp. $317-325$.

Pranzini, E., Wetzel, L. (Eds), 2008. Beach Erosion Monitoring. Results from beachmed-e / optimal Project Optimisation des Techniques Integrées de Monitorage Appliquées aux Littoraux. Florence, Italy, Nuova Grafica Fiorentina.

Puente, I., González-Jorge, H., Martínez-Sánchez, J., Arias, P., 2013. Review of mobile mapping and surveying technologies. In: Measurement, Vol. 46 (7), pp. 2127 - 2145.

Roncella, R., Forlani, G., \& Remondino, F., 2005. Photogrammetry for geological applications: automatic retrieval of discontinuity orientation in rock slopes. In: Proceedings of SPIE - The International Society for Optical Engineering (Videometrics VIII, 17). doi:10.1117/12.587822.

Trimarchi, R., Privitera, S., 2007. Pressione antropica e degrado ambientale nelle aree costiere siciliane. La dispersione del patrimonio paesaggistico della riviera dei Ciclopi. In: Annali della Facoltà di Scienze della Formazione. Università degli Studi di Catania. Catania, C.U.E.C.M., pp. 187-247. 